\title{
Organic Flash Cycles: Off-design behavior and control strategies of two different cycle architectures for Waste Heat Recovery applications.
}

\author{
A. Baccioli*, M. Antonelli \\ Department of Energy, Systems, Territory and Construction Engineering, University of Pisa, Largo Lucio Lazzarino 1, Pisa, \\ Italy \\ ${ }^{*}$ Tel:+39-050-2217137, Fax: +39-050-2217160
}

\section{Abstract}

1 Off-design characterization of energy systems has become interesting, especially for waste heat recovery 2 application, where the heat source temperature and mass flow rate can vary over time. Low-grade heat is generally converted into power through ORC modules: the problem of the constant temperature evaporation 4 lead to the definition of alternative architectures, among which organic flash cycles.

${ }_{5}$ In this work, the off-design behavior of two different architectures of single-stage Organic Flash Cycles 6 has been analyzed in steady-state condition, for small scale waste heat recovery (WHR) purposes. The main 7 difference between the two architecture is the regeneration: in the first architecture (Single-Stage Organic 8 Flash Cycle SS-OFC), the liquid of the flash evaporator, after lamination is mixed with the vapor from the 9 expander and then sent to the condenser; in the second architecture Single-Stage Organic Flash Regenerative Cycle, SS-OFRC, the liquid from the flash evaporator is mixed with the liquid from the condenser, to regenerate the cycle. The most appropriate fluid for the two cycles was selected from a list of sixteen fluids with the objective of minimizing volume flow rates and maximizing the system efficiency and i-Pentane was chosen. For the off-design behavior, a rotary volumetric expander derived from a Wankel engine was considered, taking into account the performance variation of the device at various rotating speed and pressure ratios. Three different control strategies were considered and compared in off-design analysis for both the cycle architectures: sliding-pressure, in which the expander speed was constant and flash pressure varied with the load; sliding-velocity, in which the load was controlled by the speed variation of the expander and flash pressure was retained constant; combined strategy in which the expander speed was varied to drive the flash pressure according to a function which maximized the system efficiency. Results showed that the efficiency of the two cycles was similar in all the operating field whatever was the control strategy considered: SS-OFRC demonstrated a better behavior at low temperatures of the heat source $\left(<170{ }^{\circ} \mathrm{C}\right)$, while $\mathrm{SS}-\mathrm{OFC}$ had a better efficiency at higher temperature. The maximum absolute efficiency difference in off-design conditions between the two cycles was lower than 0.3\%. SS-OFRC however had a wider field of operation than SS-OFC, due to the better flexibility of this type of cycle. As for the control strategy, with both the architectures, 
combined strategy maximized the system efficiency and flexibility for every temperature and mass flow rate of the heat source considered.

Keywords: Organic Flash Cycle; Waste Heat Recovery; Off-design; Control Strategies; Organic Rankine Cycle; ASPEN HYSYS

\section{Introduction}

ORCs play a major role in the exploitation of low-temperature heat source, due to the favorable proprieties of organic fluids, resulting in compact and simple components, reducing system size $[1,2]$ and proved to be one of the most reliable and efficient solutions for low and medium temperature waste heat recovery systems [3]. However, the presence of the constant temperature evaporation in the heat transfer process causes a bad match of the heat transfer curves, which implies exergy destruction. In the case of WHR system, the pinch point at evaporating temperature cause the discharge of the hot stream at a much higher temperature than the lowest temperature of the cycle [4]. To overcome these problems, several authors in the literature have proposed various solutions : Kalina cycles, ORC with zeotropic mixtures, supercritical ORCs, multiple level ORCs, organic trilateral cycles and organic flash cycles.

Kalina cycles have been introduced in the 1980s and work in an analogous way to Rankine cycles, but with a mixture of water and ammonia, to obtain a temperature glide during evaporation and condensation [5]. The main issue of this type of architecture is related to the complicated layout, which involves additional heat exchangers, absorber and desorber, providing however a small gain in efficiency respect to subcritical ORC [6] and operating at high pressure [7].

To obtain the same glide effect of the Kalina cycle, but with a more simple architecture, different zeotropic organic mixtures have been proposed: the use of these type of fluids has been widely studied in the literature, serving various heat source [8-10]. Due to the better match of the exchange curves, the efficiency reached by this type of cycles are higher than those of the simple ORC, however there are still some issues in their practical realization, due to uncertainty in the fluid properties, unknown heat coefficient values, cost effectiveness and above all composition and fractioning of the two fluids [11].

Supercritical ORCs represent another possibility in improving the performance of the system, reducing the entropy production during the heat exchange [12]. Moreover, the high temperature of the cycle allows to achieve a better cycle efficiency than that of subcritical ORC, if a recuperator is employed [13] and to operate with a smaller turbine [14]. The high pressure achieved in the cycle [15] and the lack of a specific design for transcritical turbines however limit the spread of this technology.

Multiple pressure level ORCs, are another solution to improve the heat transfer, by splitting the eva- 
poration on more than one pressure level. Performance of multiple level ORC are similar to that of other advanced solutions (supercritical ORC and ORC with zeotropic fluids), but with a much larger complexity which limits their use just to large scale applications [16].

Trilateral organic cycles were introduced by Smith et al. in $1993[17,18]$ with the purpose of developing a thermodynamic cycle which was as close as possible to the Lorentz cycle, which is the cycle with the best recovery efficiency for sensible heat sources and isothermal condensing conditions. The lack of an efficient two phase expander represents a great limit for this type of technology and a practical application has never been developed.

Organic Flash Cycle, are a modification of Trilateral Organic Cycle, where the saturated liquid at the end of the heat exchanger is flashed and the vapor from the flash evaporator is expanded in a conventional expander. This type of cycle is widely used in geothermal application where the heat source is composed of superheated water at very high pressure. Ho et al. in [19] hypothesized the use of the flash cycle with organic fluids for high temperature $\left(300^{\circ} \mathrm{C}\right)$ waste heat recovery applications: they tested several fluids and concluded that the system second law efficiency was slightly lesser than that obtained with ORC, due to exergy destruction during the lamination process. However, they concluded that with some improvements both in the cycle layout and in the replacement of the throttling valve with a two-phase expander a better effciency can be reached. This conclusion was validated by the results obtained in further works [20,21] where they demonstrated the superiority of two-stage flash cycles and of single-stage flash cycle with two phase expander respect to ORC. The major issue with this type of cycle is represented by the large exchanging surface required: in fact, in flash cycles, both in single and double-stages, the working fluid is heated from the condensing temperature up to the maximum cycle temperature and exchange curves are parallel. To reduce the heat exchanger area and reduce the costs, a different cycle architecture, with regeneration was designed and proposed in a previous paper [22]. The results indicated that the regenerated cycle has the same thermodynamic performance of the organic flash cycle, but achieved a largely lower specific cost, similar to subcritical ORCs.

The results obtained in the previous paper encourages further studies on this technology where an offdesign analysis is still lacking.

Off-design characterization is important to understand the evolution of many thermodynamic variables as well as of the system production. The off-design behavior of subcritical ORCs has been widely investigated in the literature, both in steady-state and transient conditions: $\mathrm{Hu}$ et al. in [23] analyzed the off-design behavior of a small scale ORC for geothermal purposes with radial turbine equipped with Variable Inlet Guided Vanes (VIGV) to evaluate different control strategy and to define the optimal angle of incidence of the VIGV. The analysis was carried in steady-state. Other authors [24-28] analyzed the off-design of various ORC systems in transient condition to define the dynamic behavior and evaluate different control strategies 
and variables to drive the system.

This paper aims to fill the gap in the knowledge of the organic flash cycles, by analyzing and comparing the off-design behavior of two different architectures of single stage organic flash cycle: Single-stage Organic Flash Regenerative Cycle (SS-OFRC) and Single-stage Organic Flash Cycle (SS-OFC). OFRCs were introduced and compared in design condition with OFCs from the thermodynamic and economic point of view in a previous paper [22], showing the same thermodynamic performances of OFCs, but a much lower cost. However a offdesign analysis of this technology has been still lacking and are the address of this paper. Despite the single flash configuration does not allow to achieve high thermodynamic performance, differently from double flash configuration, the off-design characterization is important to define the control strategies and understand the effect of the regeneration on the system behavior. The results obtained can be considered as a basis in the study of flash cycle configurations and a further analysis on the double stage architecture will be presented in a further paper. Firstly, the most suitable working fluid has been chosen in design condition among a series of organic fluids, and all the main components of the WHR system have been designed. For the off-design analysis, three different control strategies have been analyzed. To the authors knowledge this is the first time that the off-design behavior of Organic Flash Cycles and their variations are analyzed in off-design conditions with different control strategies.

\section{Methodology}

\subsection{Organic Flash Cycles and Organic Flash Regenerative Cycles}

In the Single Stage Organic Flash Cycle (SS-OFC) for WHR applications [19] (fig. 1 A), the working fluid is pumped by a pump and warmed up to the saturation temperature in the main heat exchanger; after the heat exchanger the fluid is laminated through a throttling valve and vapor and liquid phase are separated in the flash evaporator. The vapor is sent to the expansion device, while the liquid is laminated through a second throttling valve and mixed with the vapor from the turbine. The mixture is therefore sent to the condenser and the cycle re-begins. As from the T-s diagram (fig. $1 \mathrm{~B}$ ), due to the single phase heating, the exchange curves are very close each other, reducing exergy destruction and limiting the exergy loss due to the low temperature of the hot stream discharged. However, the large amount of heat transferred to the cycle and the small medium temperature difference between the exchanging curves, requires large exchange area, thus increasing the cost of the heat exchanger. Moreover, the irreversibility caused by the two throttling valves, reduces the cycle efficiency, increasing the heat rejected to the condenser and requiring large condensing surface. For these reasons an improvement of the cycle architecture is necessary.

The enthalpy of the liquid inside the flash evaporator can be exploited to increase the exchanger inlet temperature and to reduce the amount of heat exchanged. In the Single Stage Organic Flash Regenerative 

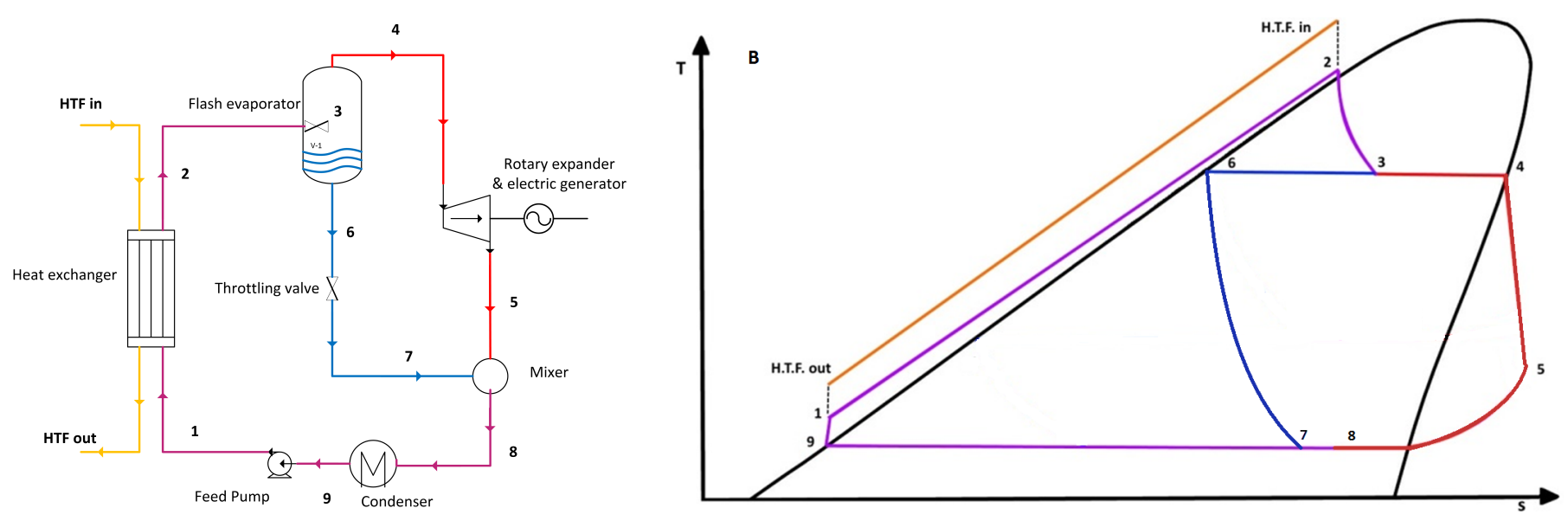

Figure 1: OFC scheme (A) and OFC T-s diagram (B).
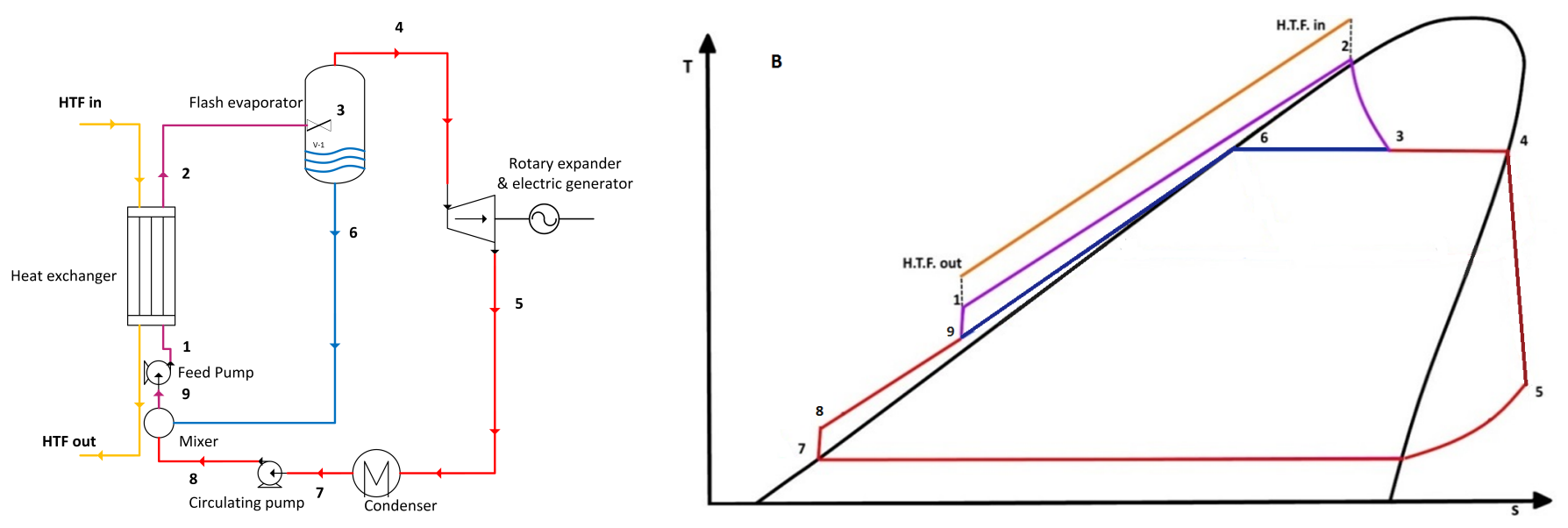

Figure 2: OFRC scheme (A) and OFRC T-s diagram (B). 
Cycle (SS-OFRC), the working fluid passes through the heat exchanger where is warmed up to the saturation temperature; after the exchanger, the fluid is laminated by the throttling valve and vapor and liquid phase are separated. The vapor is expanded and then condensed. In this configuration, the liquid from the flash evaporator is mixed with the liquid pumped from the condenser outlet and then after the pump is again sent to the exchanger to restart the cycle (fig. 2). The regeneration, besides limiting the amount of heat exchanged, increases the cycle efficiency, contributing to limit the heat rejected to the condenser and reducing the size of this device. The limited heat rejected to the codenser resulted in a lower exchange area for the condenser of the SS-OFRC than that of SS-OFC: considering also the reduction of the surface of the main heat exchanger, SS-OFRC requiered a lower global exchange area than SS-OFC, which can reduce the cost of the system.

In this paper, the heat source at the design point was composed of a stream of $540 \mathrm{~kg} / \mathrm{h}$ of superheated water at the temperature of $180^{\circ} \mathrm{C}$, resulting in an available heat of about $100 \mathrm{~kW}$.

\section{$2.2 \quad$ Fluid selection}

As for ORCs, the selection of the proper working fluid for SS-OFC and SS-OFRC has a strong influence on the operating conditions of the cycle. Many criteria can lead to the choice of the best fluid, such as thermodynamic performance, heat exchanger area, maximum pressure of the plant, type of expander, feed pump power consumption, environmental impact and cost.

In this work, a small scale WHR was considered with a volumetric rotary expander derived from a Wankel engine, whose prototype has been built and experimented at the University of Pisa. For this reason the priority was given first of all to the value of the volume flow rate through the expander and the condenser. Overall efficiency and environmental impact (zero ozone depleting potential fluids) were also considered in this work. Global efficiency was evaluated as:

$$
\eta=\frac{\dot{Q}_{e x c h}}{\dot{Q}_{a v}} \cdot \frac{\dot{W}_{N E T}}{\dot{Q}_{e x c h}}=\varepsilon \cdot \eta_{c y c}=\frac{\dot{W}_{N E T}}{\dot{Q}_{a v}}
$$

Where $\dot{Q}_{\text {exch }}$ is the exchanged heat, $\dot{Q}_{a v}$ is the available heat, defined as the maximum heat which can be exchanged, leading the heat source to the ambient conditions (i.e. $\left.\dot{Q}_{a v}=\dot{m}\left(h_{i n}-h_{0}\right)\right), \dot{W}_{N E T}$ is the net power output, $\varepsilon$ is the recovery efficiency, $\eta_{c y c}$ is the cycle efficiency and $h_{0}$ is the enthalpy of the HTF at ambient conditions $\left(20^{\circ} \mathrm{C}\right.$ and 1.01 bar $)$.

Overall efficiency obtained with SS-OFC at the design point $\left(\mathrm{T}_{\mathrm{HTF}}=180^{\circ} \mathrm{C}\right.$ and $\left.\mathrm{m}_{\mathrm{HTF}}=520 \mathrm{~kg} / \mathrm{h}\right)$ for various fluids are summarized in the graph of fig. 3 and in table 1, considering a constant isentropic efficiency of 0.7 for the expander. The trend obtained in the case of SS-OFRC is similar and not reported for the 


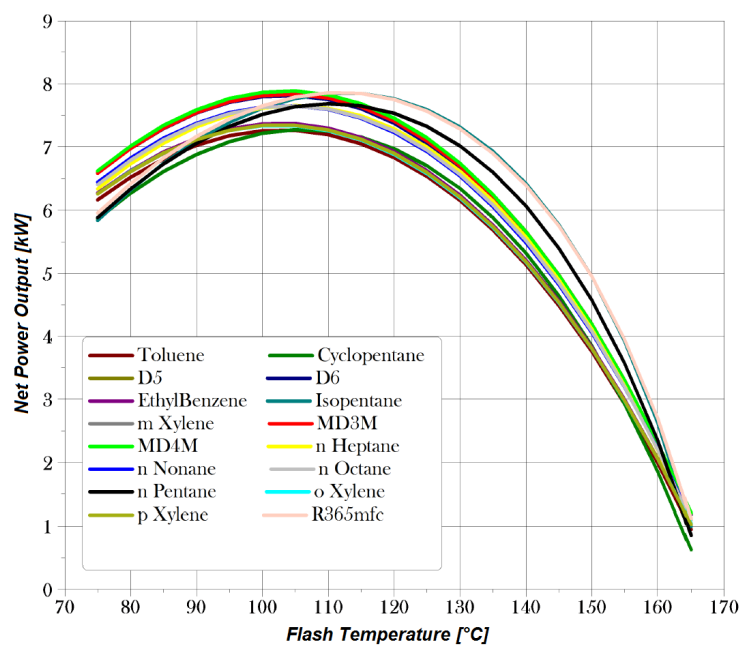

Figure 3: Efficiency of SS-OFC for various flash temperature at $T_{H T F}=180^{\circ} \mathrm{C}$.

sake of brevity. The overall efficiency is maximized by a unique flash temperature for each fluid. I-Pentane provided the best efficiency value among the tested fluids, a low flow rate across the expander and the highest value of the figure of merit $\Delta h / v_{g}$. This last figure of merit was firstly introduced in [29] and used in the economic analysis carried on double-stage flash cycles, published in a previous paper [22], since it provides preliminary information about the condenser size. In fact, being the ratio between the condensing heat and the volume flow rate, it represents the amount of heat exchanged for unit hardware cost: in other words, the higher is the value of the figure of merit, the larger is the heat exchanged for a given volume and smaller is the condenser. As an example, for syloxanes (D5, D6, MD3M and MD4M), which are characterized by a relatively low specific condensing heat and have a very large specific volume at condensing pressure, present a low value of the figure of merit and will require a large condenser. Conversely, N-Pentane and I-Pentane have a high vapor density which reduces the value of the figure of merit and therefore the size requested for the condenser. Due to the favorable characteristics of i-Pentane, which led to high efficiency and aimed to reduce the size of both expander and condenser, this fluid was selected as working fluid for the off design analysis of the SS-OFC and SS-OFRC.

It is worth to notice that differently from [19], where the heat source was a constant stream at $300^{\circ} \mathrm{C}$, single stage organic flash cycle can be competitive respect to ORC in some particular heat source conditions (fig. 4, obtained with i-Pentane as working fluid and with a constant isentropic efficiency of 0.7 for the expander). In fact, when the heat source temperature is near the critical point, the quantity of vapor separated by the flash evaporator increases (the two phase region is narrow) and the flash cycle can provide a higher output power than the ORC. From the analysis of the figure, it is evident that the regenerative solution always provide the lowest overall efficiency, if compared with the non regenerated cycle. This result however was obtained with a fixed isentropic efficiency. For lower values of isentropic efficiency the regenerative cycle can reach a better thermodynamic performance than SS-OFRC. 


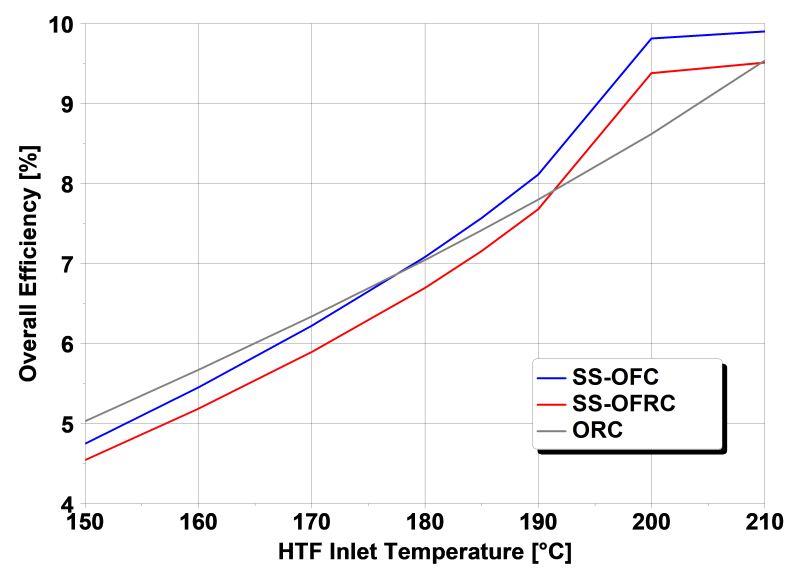

Figure 4: Overall efficiency comparison for SS-OFC, SS-OFRC and ORC with a fixed turbine isentropic efficiency and $i$-Pentane as working fluid.

\begin{tabular}{lcccc}
\hline & $\begin{array}{c}\text { Critical } \\
\text { Temperature }\end{array}$ & $\begin{array}{c}\frac{\Delta h}{v_{g}} \\
{\left[{ }^{\circ} \mathrm{C}\right]}\end{array}$ & $\begin{array}{c}\text { Volume } \\
\text { flow rate }\end{array}$ & Overall Efficiency \\
& 319 & $\left.73 . \mathrm{m}^{3}\right]$ & $\left.\mathrm{m}^{3} / h\right]$ & \\
\hline Toluene & 344 & 28.24 & 91.3 & 7.20 \\
Ethylbenzene & 357 & 20.50 & 214.1 & 7.30 \\
o-Xylene & 344 & 25.02 & 186.9 & 7.26 \\
$m$-Xylene & 343 & 26.13 & 186.9 & 7.27 \\
$p$-Xylene & 380 & 0.05 & 183.1 & 7.27 \\
MD4M & 355 & 0.28 & 8232.6 & 7.83 \\
MD3M & 346 & 0.85 & 2762.3 & 7.78 \\
D5 & 373 & 0.15 & 1480.4 & 7.75 \\
D6 & 321 & 14.49 & 4382.5 & 7.59 \\
$n$-Nonane & 296 & 40.29 & 253.1 & 7.60 \\
$n$-Octane & 267 & 112.88 & 121.4 & 7.62 \\
$n$-Heptane & 239 & 588.76 & 67.6 & 7.26 \\
Cyclopentane & 197 & 884.33 & 15.7 & 7.69 \\
$n$-Pentane & 187 & 1119.45 & 23.5 & 7.85 \\
$i$-Pentane & 187 & 813.17 & 17.8 & 7.86 \\
R365mfc & &
\end{tabular}

Table 1: System efficiency, expander volume flow rate and figure of merit value for various fluids. 


\begin{tabular}{lccc}
\hline & & OFC & OFRC \\
\hline Geometry type & BFM & BFM \\
Tube numbers & $100^{*}$ & 168 \\
Tube Outer Diameter & {$[\mathrm{mm}]$} & 12.7 & 12.7 \\
Tube Lenght & {$[\mathrm{m}]$} & 7.90 & 6.09 \\
Shell Diameter & {$[\mathrm{mm}]$} & 219 & 273 \\
Effective Exchange Area & {$\left[\mathrm{m}^{2}\right]$} & 77.7 & 41.3 \\
UA in Design Conditions & {$[k W / K]$} & 13.95 & 9.37 \\
Pressure Drop in design conditions (working fluid) & {$[\mathrm{kPa}]$} & 7.9 & 3.8 \\
Pressure Drop in design conditions (HTF) & {$[\mathrm{kPa}]$} & 1.9 & 0.9 \\
Exchanger Cost & $\$$ & 23100 & 19500 \\
\hline *Lowfin Tubes & & & \\
\hline
\end{tabular}

Table 2: Exchanger geometry for the OFC and OFRC.

\begin{tabular}{lccc}
\hline & & OFC & OFRC \\
\hline Geometry type & BEM & BFM \\
Tube numbers & 183 & 247 \\
Tube Outer Diameter & {$[\mathrm{mm}]$} & 12.7 & 12.7 \\
Tube Lenght & {$[\mathrm{m}]$} & 2.55 & 1.80 \\
Shell Diameter & {$[\mathrm{mm}]$} & 273 & 323 \\
Effective Exchange Area & {$\left[\mathrm{m}^{2}\right]$} & 18.6 & 17.5 \\
UA in Design Conditions & {$[\mathrm{kW} / \mathrm{K}]$} & 16.0 & 7.8 \\
Pressure Drop in design conditions (working fluid) & {$[\mathrm{kPa}]$} & 1.79 & 0.69 \\
Pressure Drop in design conditions (HTF) & {$[\mathrm{kPa}]$} & 0.19 & 0.325 \\
Exchanger Cost & $\$$ & 13900 & 13000 \\
\hline
\end{tabular}

Table 3: Condenser geometry for the OFC and OFRC

\subsection{System Design}

\subsubsection{Heat exchangers}

The main heat exchanger and condenser were designed with a pinch point of $10^{\circ} \mathrm{C}$ and an approach point of $12^{\circ} \mathrm{C}$, in ASPEN EDR (Exchanger Design and Rating). The actual geometry was evaluated by minimizing the exchanger cost. The obtained geometry was then transferred to ASPEN HYSYS which for each variation of the mass flow rate and temperature of the two streams evaluated the value of the product $U \cdot A$ and therefore the exchanged heat. The detailed geometry of both the exchanger and condenser is reported in tables 2 and 3 for both the SS-OFC and the SS-OFRC. As for the condenser, cooling water at $15^{\circ} \mathrm{C}$ was considered with a thermal gradient of $15^{\circ} \mathrm{C}$ across the condenser.

From the design process, the exchanger and the condenser of the SS-OFC were much larger than those of the SS-OFRC. The larger exchanged area results in higher equipment cost for the SS-OFC respect to the SS-OFRC (tab. 2 and 3).

\subsubsection{Expander}

Concerning the expander, a rotary volumetric expander derived from Wankel engine was supposed to be used. A prototype of this expander was developed at the University of Pisa and in previous papers a numerical 

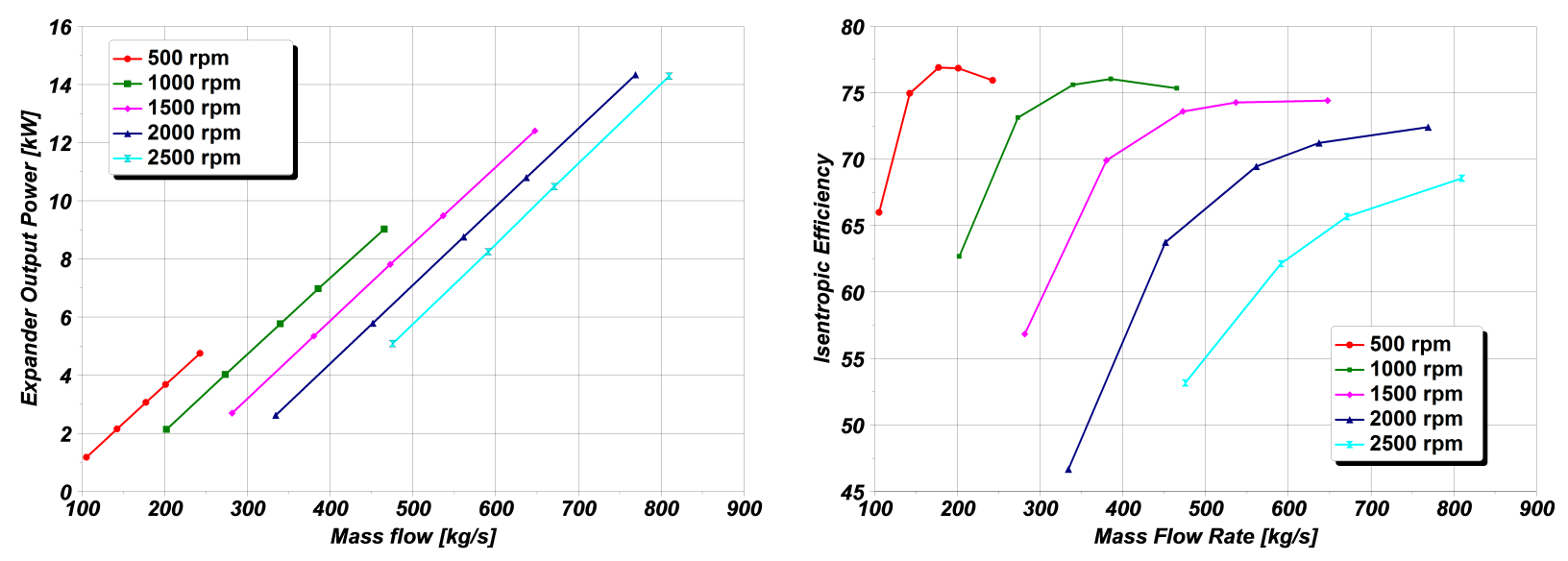

Figure 5: Expander Maps

model was modeled and calibrated with experimental data, carried out using both steam and air. [30, 31].

Flux and effectiveness of the expander are two important variables which affects the global behavior of the system and therefore cannot be considered constant in the off-design analysis. To this purpose, the numerical model of the expander was used to extrapolate the operating curves of the expander for different pressure ratio and rotating speed (fig. 5). From the simulation the optimal results in terms of isentropic efficiency were reached with a cut-off of 0.15 . In a volumetric expander, the cut-off is the ratio between the equivalent volume swept with the intake valve opened and the equivalent displacement of the device: this parameter has a direct influence on the expansion ratio and therefore on the value of the pressure in the expander chamber at the exhaust valve opening. The optimal equivalent displacement of the rotary expander for both the two cycle was $800 \mathrm{~cm}^{3}$, to limit the rotating speed in the range 500-2500 rpm, typical of this expander.

\subsubsection{Pumps}

Centrifugal pumps were considered for both the cycles. Similarly to the expander, the variation of effectiveness and of the flow of the device should be considered when analyzing the off-design. The pumps were designed by defining the nominal conditions in ASPEN HYSYS and generating the off-design curves. HYSYS automatically generates a set of curves based on different speeds and pump loads as reported in [32].

\subsection{Control strategies}

When operating in off-design conditions, the choice of a proper control strategy is a key factor. In this paper the Waste Heat Recovery system is analyzed supposing the FWH (Following the Waste Heat) operation, i.e. the thermal power transferred to the power unit is not controlled, conversely to the FEL (Following the Electric Load), where the thermal power transferred to the cycle is regulated by a by-pass valve on the heat exchanger to follow the electric load. In the case of FWH systems, the single stage organic flash cycles, similarly to subcritical ORCs, can operate according three different control strategies: 
- in a first strategy, the output power varies due to flash pressure variation, and the expander rotates at constant speed: analogously to the ORCs, this control strategy is defined sliding-pressure and is the simplest control strategy that can be achieved, since the expander speed is constant;

- in a second control strategy, the output power is controlled by the expander speed variation, which varies to keep the flash pressure to a constant set-point value: similarly to the ORCs, this control strategy is defined sliding-velocity;

- in the third control strategy, both the pressure and the expander speed are varied: the flash pressure is regulated by the expander speed according to a proper function to optimize a system variable (such as maximization of the system efficiency, as in the case of this paper, or minimization of the cost of energy etc.): this control strategy is a combination of both sliding-pressure and sliding-velocity.

The upper temperature of both the two cycles, with any control strategy, is regulated by the working fluid mass flow rate through the heat exchanger, and therefore by the pump speed. The maximum pressure of the cycles instead is controlled by the throttling valve in the first flash evaporator. The condensing pressure and the subcooling instead, once established the working fluid mass flow rate were controlled by the mass flow rate of the coolant. Since the two cycles were simulated in steady-state conditions, the values of these variables were evaluated, for each simulation and with any control strategy, by an optimization algorithm, in order to evaluate the maximum cycle temperature, pressure and cooling water mass flow rate which maximized the output power of the two cycles, with the constraint of keeping the stream in single phase. Regarding the condensing pressure, due to the limited variation expected (the inlet temperature of the cooling water was constant), a constant value of 1.09 bar was adopted, to reduce the optimizer calculation time.

\subsection{Aspen HYSYS model}

As stated in the previous lines, the model of the recovery system with the two types of working cycle, was developed in Aspen HYSYS. This software is a process simulator that can perform design and part-load analysis of various plants, and allows to optimize processes: several optimization alghorithm are available within the code.

In the case of this paper, and for both the cycles, the system was optimized in design conditions, taking into account the behavior of the expander. Heat exchangers were then directly designed inside the simulation environment, by using the tool ASPEN Exchanger Design and Rating: commercial heat exchanger were chosen, applying the criterion of minimizing the exchange area. In a similar manner, both pumps and flash separators were designed and sized. Once that the geometry was defined, the software allowed to simulate the off-design conditions. The software discretizes the heat exchangers in various nodes and in each node evaluates the heat exchange coefficient and therefore the thermal exchange. According to the expander maps, 
reported in fig. 5, and to the expander boundary conditions, the software manages establishing the rotating speed of the expander. The software iterates the calculations on the various devices of the cycle to balance both mass and energy conservation equations.

\section{Results and discussion}

As reported above, simulations were carried in steady-state conditions for both the cycles. The BOX optimization algorithm was adopted to find the variables which maximized the net power output, which, with the exception of the maximum cycle temperature and pressure, are different from control strategy to control strategy.

\subsection{Sliding-Pressure}

For the sliding-pressure control strategy, a constant expander speed was used as a constraint for the optimizer, while flash pressure was evaluated by the optimization algorithm, together with the maximum cycle temperature and pressure. The mass flow of cooling water was also evaluated in the optimization process.

Keeping the HTF mass flow rate constant at the design point, the overall efficiency increased with the HTF temperature (fig. 6): SS-OFRC had a better efficiency at low values of HTF temperature, while OFC became slightly more efficient at higher temperatures $\left(170-180^{\circ} \mathrm{C}\right)$. This behavior depends on the different trend of the cycle efficiency and recovery efficiency of the two cycles at different heat source temperatures: the recovery ratio of the SS-OFRC, in fact, decreased with HTF temperature, causing a reduction in the increase of the cycle efficiency with the heat source temperature. At a first look, this result might seem to be unconsistent with that showed in fig. 4, where the overall efficiency of the SS-OFC was always higher than that of SS-OFRC. However, it is worth to notice that the results of fig. 4 were obtained keeping the isentropic efficiency of the expander and the pinch and approach point constant. The real performance of the two cycles in off-design conditions, is influenced by the behavior of both the heat exchangers and of the expansion device.

For both the two cycles, the rotating speed of the expander which maximized the system efficiency was comprised between 1000 and 1500 rpm. Higher velocity caused a decrease of the flash pressure (fig. 7) which reduced the output power. It is worth to notice that, in the case of SS-OFRC and with a rotating speed of the expander of $1000 \mathrm{rpm}$, the operating field of the system is extended up to the HTF temperature of $210^{\circ} \mathrm{C}$, with the design equipment. In this condition the approach point and the pinch point of the heat exchanger largely increased to allow the heat transfer through the heat exchangers, thus reducing the increase in overall efficiency with the HTF temperature (fig. 6, right). The high flash pressure, however granted a high regeneration temperature, thus limiting the heat exchanged and keeping the cycle efficiency at a high value, 

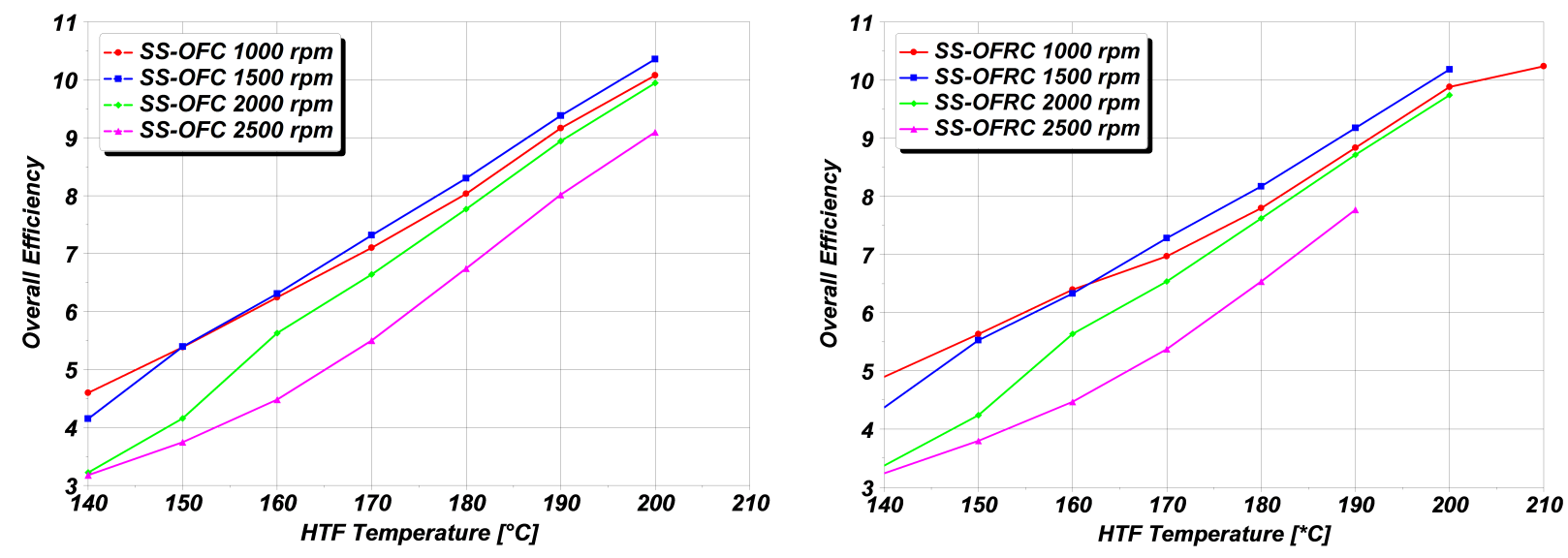

Figure 6: Overall Efficiency for SS-OFC (left) and SS-OFRC (right), for a variation of the HTF temperature: sliding-pressure.
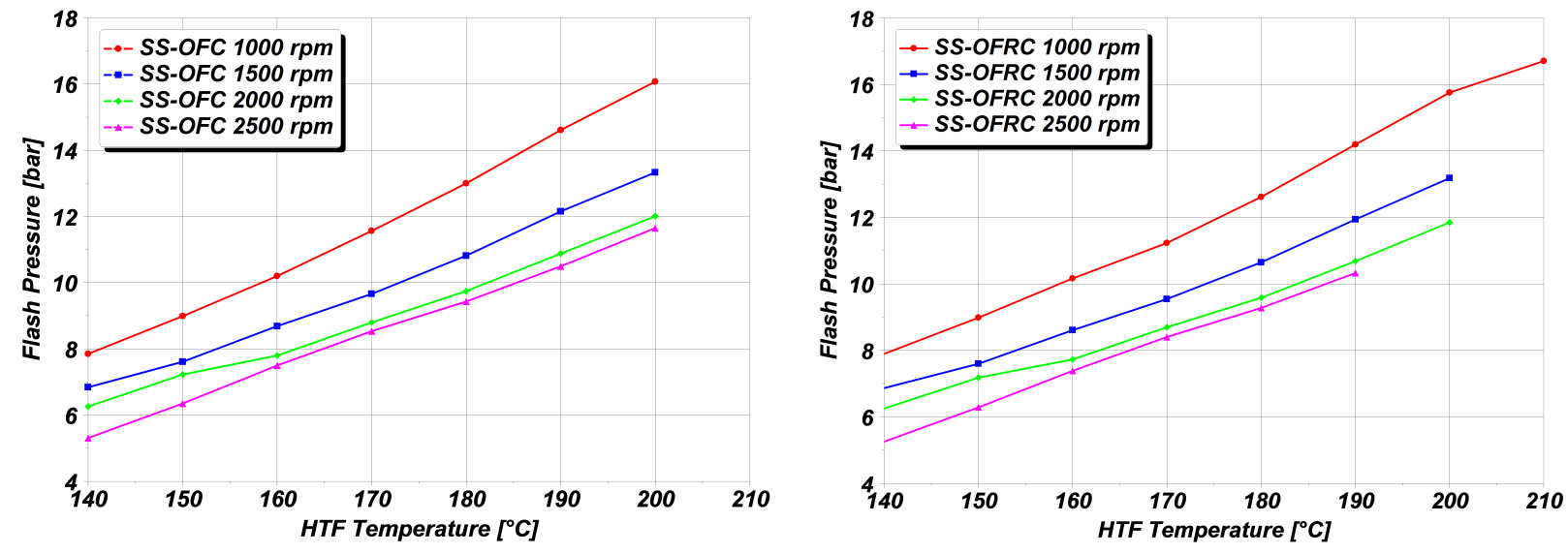

Figure 7: Flash pressure for SS-OFC (left) and SS-OFRC (right), for a variation of the HTF temperature: sliding-pressure.

allowing the complete condensation of the working fluid in the condenser. This working point has never been achieved with SS-OFC, due to the lack of regeneration: in fact, in this condition, pinch and approach point were higher than those of SS-OFRC, resulting in a lower value of the maximum cycle temperature; this fact, coupled with the absence of regeneration, reduced the efficiency of the cycle. In this condition, furthermore, the condenser resulted to be undersized and therefore unable to exchange the condensing heat. A further sizing of the heat exchanger and of condenser would have been necessary to make SS-OFC working at this temperature. A similar behavior was found for the SS-OFRC when operating at the fixed velocity of 2500 rpm: in this case the maximum operative $\mathrm{HTF}$ temperature was found to be $190^{\circ} \mathrm{C}$ : in these conditions, in fact, the flash pressure was so low (fig. 7) to cause a reduction in the regeneration process and therefore in the cycle efficiency which led to the condenser failure. Also in this case a re-size of this device would solve the problem.

With respect to mass variations (fig. 8), the optimal speed which maximized the overall efficiency with 

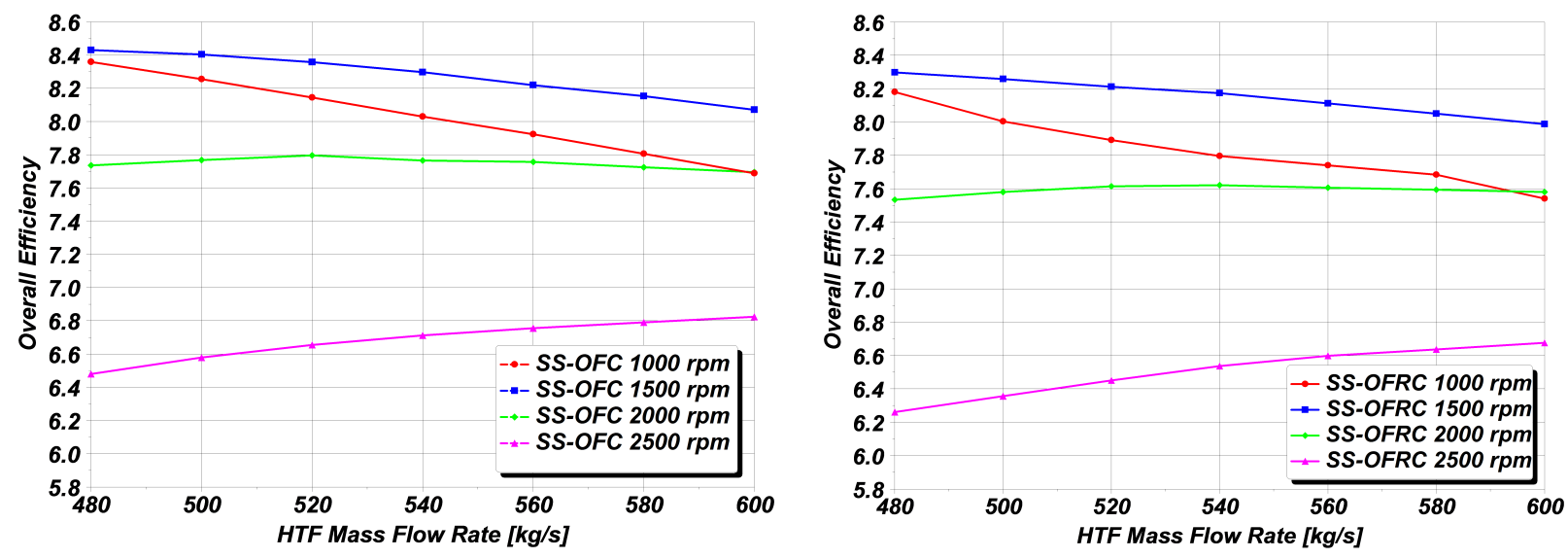

Figure 8: Overall Efficiency for SS-OFC (left)and SS-OFRC (right), for a variation of the HTF mass flow rate: sliding-pressure.
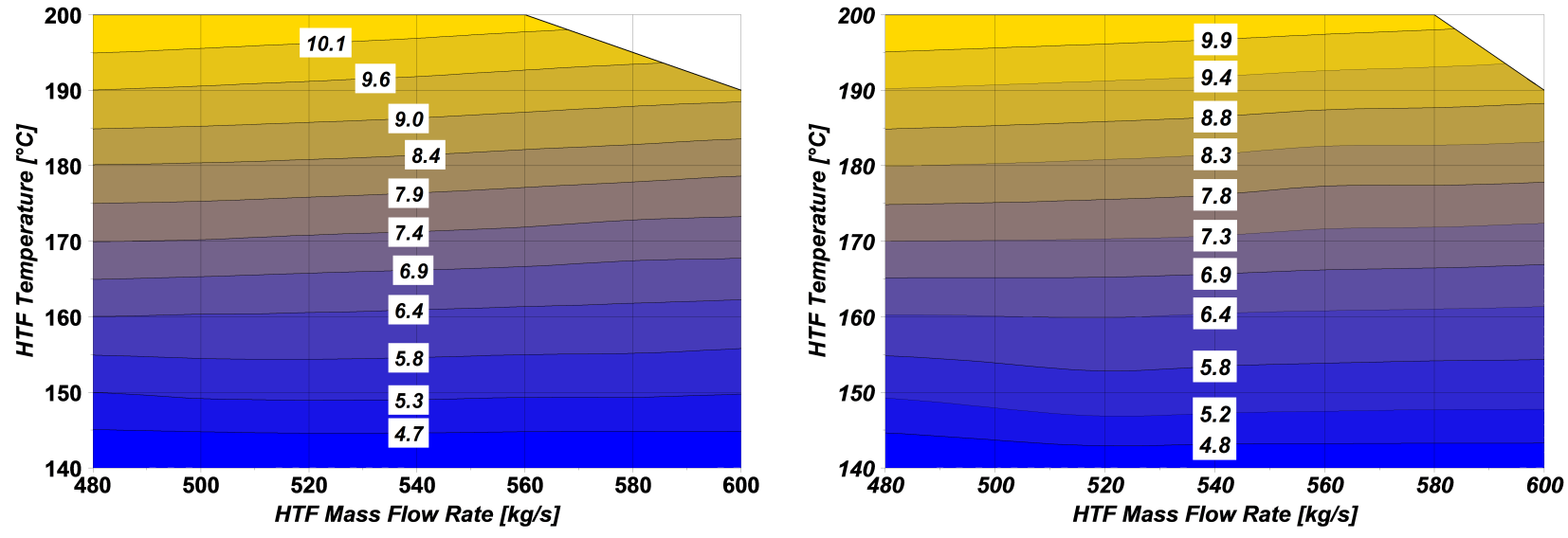

Figure 9: Maps of global efficiency for sliding-pressure control strategy: SS-OFC (left), SS-OFRC (right).

this type of control strategy was always in the range between 1000 and $1500 \mathrm{rpm}$, with the HTF temperature at the design value $\left(180^{\circ} \mathrm{C}\right)$ : this is the result of the trade-off between the work increase, due to the increase of the working fluid mass flow rate and to the reduction of the flash pressure, wich reduces the cycle efficiency . At this temperature the efficiency of the SS-OFC was slightly higher than that of SS-OFRC. From the analysis of efficiency maps, reported for a rotating speed of $1500 \mathrm{rpm}$ (fig. 9), the efficiency of the SS-OFC was often slightly higher than that of SS-OFRC with the sliding-pressure control strategy. This last however provided a wider field of operation due to the large number of degree of freedom of the regenerative architecture.

\subsection{Sliding-velocity}

In the case of the sliding-velocity control strategy, the flash-pressure is kept constant by the vapor volume flow rate, through the variation of the expander speed. In ASPEN HYSYS, the flash pressure was imposed and the expander speed was evaluated by the code. The optimization algorithm evaluated the values of maximum temperature and pressure of the cycle and the mass flow rate of the cooling water at the condenser 

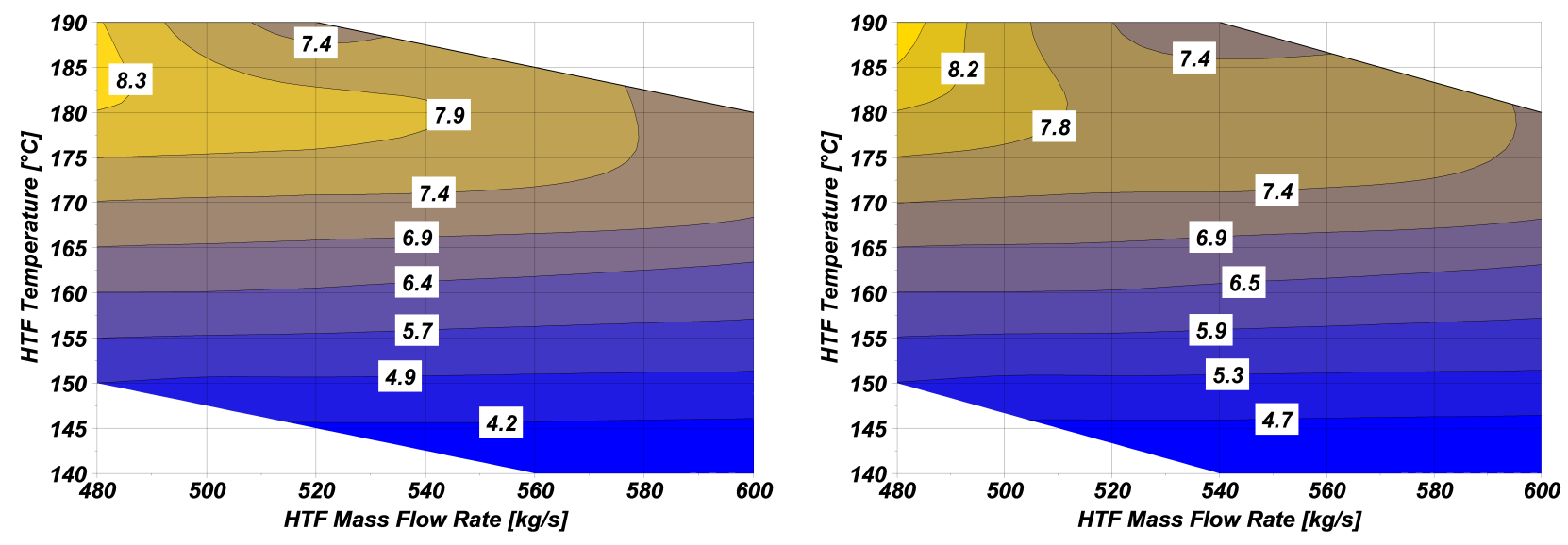

Figure 10: Maps of global efficiency for sliding-velocity control strategy: SS-OFC (left), SS-OFRC (right).

which maximizes the system efficiency. With this control strategy, the expander speed was limited in the range 500-2500 rpm. In fact below $500 \mathrm{rpm}$ the delivered power was very low (fig. 5) while above 2500 rpm the isentropic efficiency of the expander sharply decreased. Within this range of expander speed, both the two systems presented a limited operation capacity. The widest operation field for both the two cycle architectures was between 8 and 10 bar. In fig. 10 the maps of operation for both the cycles with the sliding-velocity control strategy are reported for the flash pressure of 10 bar.

The trend of the overall efficiency is quite similar for both the two cycles: as for the sliding-pressure control strategy, the SS-OFRC presented higher efficiency at low temperatures of the heat source, while SS-OFC was more efficient at high temperature. From the comparison with sliding-pressure control strategy, the sliding-velocity control strategy provided lower values of overall efficiency for both the two cycles in all the operating field at the flash pressure of 10 bar which maximized the system efficiency. Due to the lower efficiency and to the smaller operating field obtained with this control strategy, it is possible to conclude that these type of cycles should not be controlled with this type of strategy.

\subsection{Combined strategy}

The combined strategy is a control strategy that combines both sliding-pressure and sliding-velocity control strategy, increasing the degrees of freedom of the control system. In this control strategy, the expander controls the flash pressure, as in the case of the sliding-velocity but, differently from this last, the flash pressure varies according to a suitable function. This function, as an example, can aim to maximize the global efficiency of the system or the economic profit or to minimize the levelized cost of energy. In this work, the maximization of the system efficiency has been considered. The optimal values of flash pressure, expander speed, maximum cycle pressure and temperature and cooling-water mass flow rate were evaluated by the optimization algorithm for each working point. 


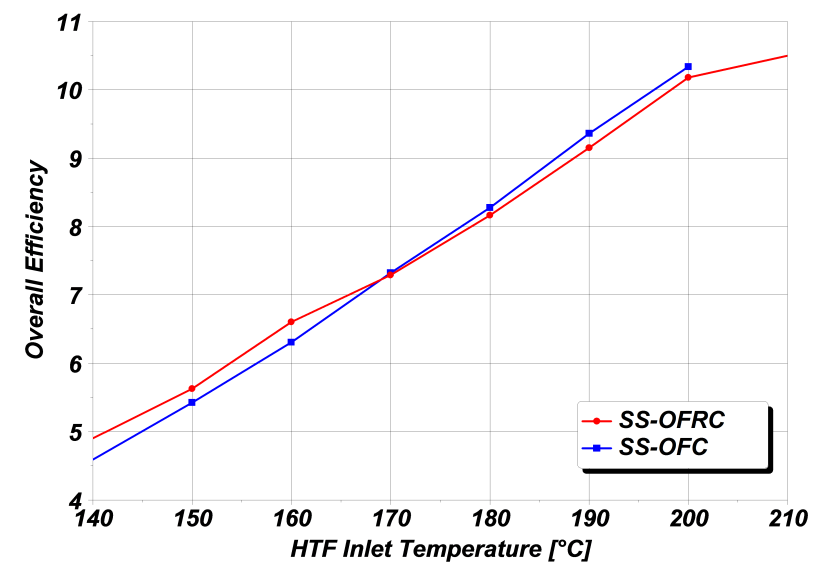

Figure 11: Overall efficiency for OFC and OFRC at design HTF mass flow rate.

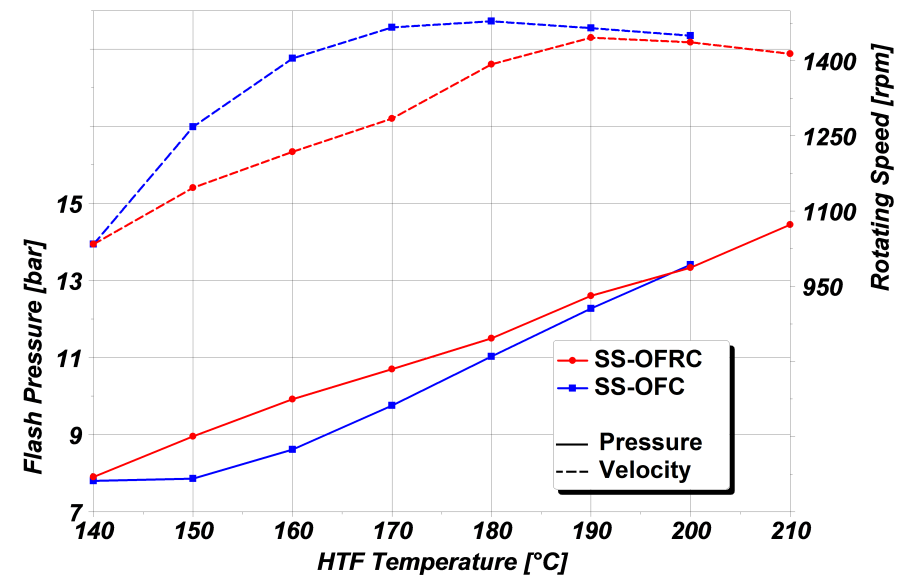

Figure 12: Flash pressure and expander rotating speed for SS-ORC and SS-OFRC with combined control strategy: HTF temperature variation.

Keeping the HTF mass flow at a constant value, the efficiency increased with the HTF temperature for both the two cycles (fig. 11), in a similar way to the other control strategies. The overall efficiency was higher, for each configuration than that obtained with the other two control strategies, due to the increase of the degrees of freedom, with the variation of both expander speed and flash pressure (fig. 12). The overall efficiency of both the two cycles (fig. 11) assumed almost the same value in all the operating range: SS-OFC provided higher performances at high HTF temperature, while SS-OFRC had better performances at low temperature. The maximum absolute difference between the two cycles, at the design mass flow rate was however lower than $0.3 \%$.

As from fig. 11, the operative field of the SS-OFRC was wider than that of SS-OFC, being this type of cycle able to work to a maximum $\mathrm{HTF}$ temperature of $210^{\circ} \mathrm{C}$ : in fact, with the combined control strategy, the combination of rotating speed and flash pressure allowed not only to follow the load variation, but also to vary the temperature of the regeneration, thus increasing the temperature at the exchanger inlet (fig. 13 left) and reducing the heat exchanged and therefore the thermal load on the heat exchanger. In this way 

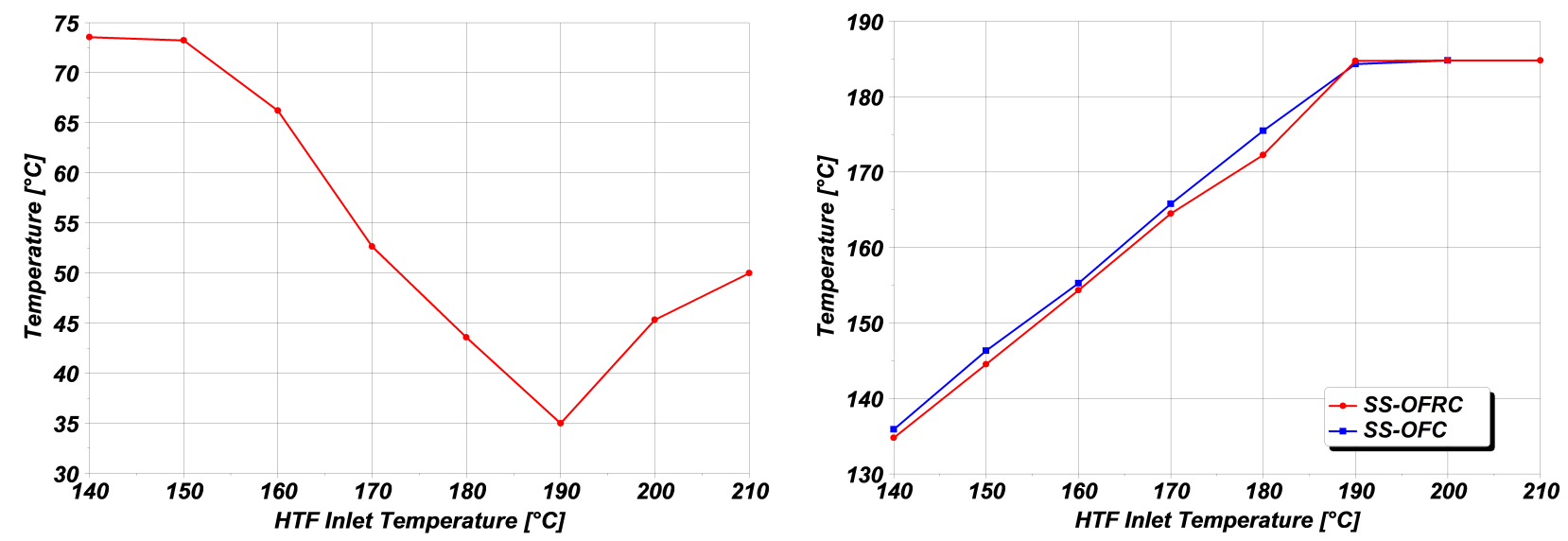

Figure 13: Temperature of the working fluid at the heat exchanger inlet for the SS-OFRC (right) and maximum cycle temperature for SS-OFRC and SS-OFC (left).

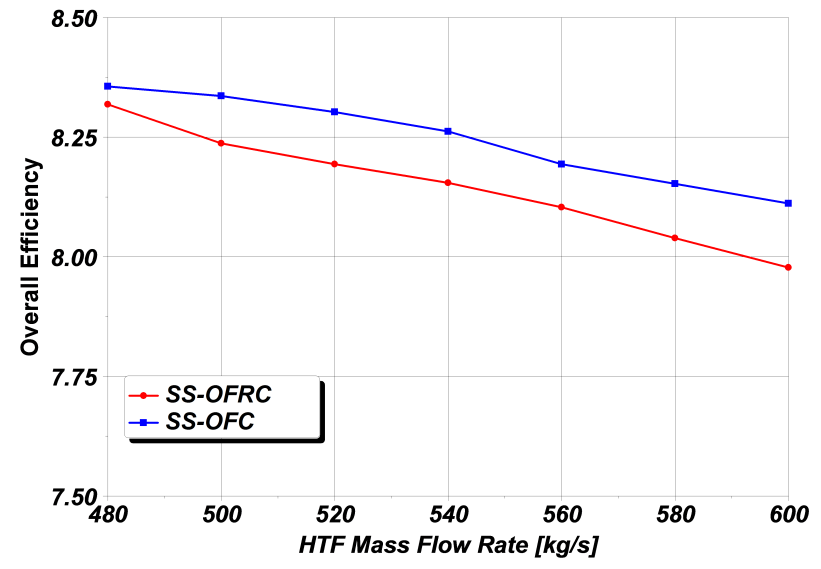

Figure 14: Overall efficiency for OFC and OFRC at design HTF mass flow rate.

the SS-OFRC had one more degree of freedom than SS-OFC, which allowed the operation to higher HTF temperature. The maximum temperature of the cycle, controlled by the mass flow rate (and therefore by the pump) growth with the HTF inlet temperature for both the two cycles, with the exception of the highest temperature, to avoid the operation at supercritical conditions.

The variation of the efficiency with the mass flow rate at the design point is reported in fig. 14 for both the cycles. The mass flow rate of the working fluid increased with the HTF mass flow rate, causing an increase of the expander speed and leading to a reduction of the isentropic efficiency of the expander, which assumed its maximum value for low values of the rotating speed (500-1000 rpm, fig. 5). Moreover, the increase of the mass flow rate cause an increase of the pressure drop through the heat exchangers. Hence, the decrease of the overall efficiency for both the two cycles with the increase in mass flow rate. The efficiency of the SS-OFC (fig. 14) was slightly higher than that of the SS-OFRC at this HTF temperature for all the HTF mass flow rate tested.

Regarding the operating range, SS-OFRC showed a wider operating map than SS-OFC (fig. 16), which 


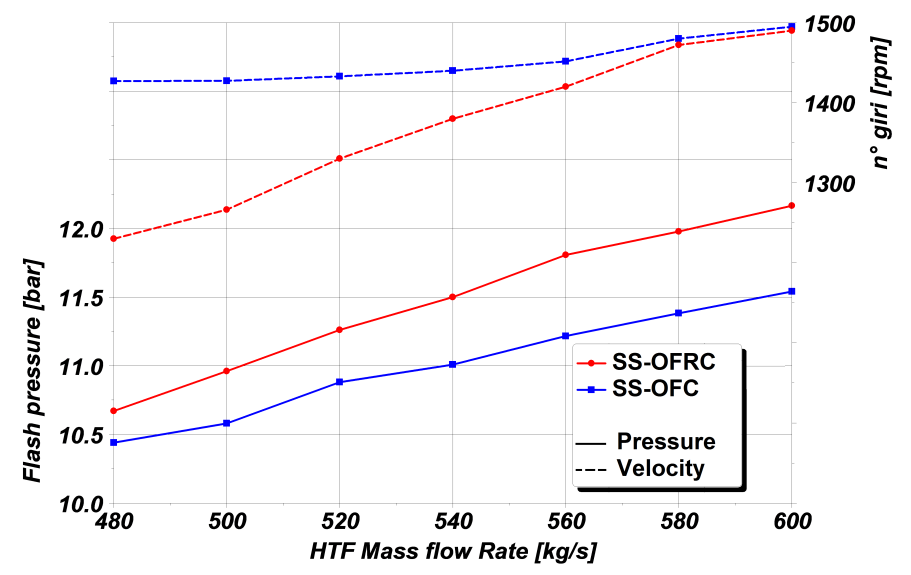

Figure 15: Flash pressure and expander rotating speed for SS-ORC and SS-OFRC with combined control strategy: HTF mass flow variation.
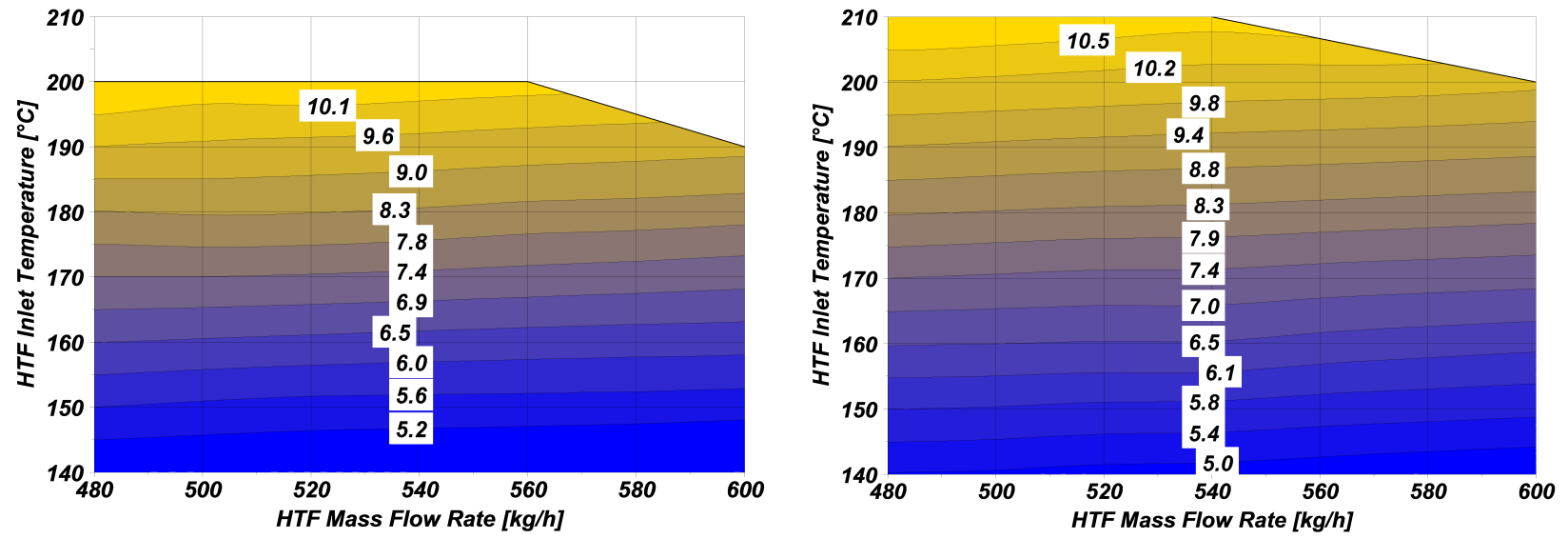

Figure 16: Working Maps for OFC (left) and OFRC (right) with combined control strategy. 
allowed to run the cycle with a temperature of the HTF fluid up to $210^{\circ} \mathrm{C}$. As stated before, in the case of SS-OFRC, the possibility of varying the flash pressure, also allowed to control the regeneration with two beneficial effects:

- increasing the heat exchanger inlet temperature, with a reduction of the heat transferred in the main heat exchanger and allowing the heat exchange of the working fluid up to high temperature;

- keeping a high cycle efficiency, which allowed to limit the heat rejected to the condenser.

In the case of SS-OFC, instead the variation of the flash pressure had no influence on the main exchanger inlet temperature, where the working fluid is always heated from the condensing temperature up to the maximum cycle temperature. In this case, the only way to reduce the heat exchanged amount at high HTF temperature was to increase the approach and pinch point. However, the reduction of the approach point led to a reduction of the maximum cycle temperature and therefore to a reduction of the cycle efficiency with an increase of the heat rejected by the condenser. For this reason SS-OFC were unable to operate with the same high temperature of the SS-OFRC.

Among the three strategies proposed, the combined one provided the best results in terms of both efficiency and flexibility, due to the larger number of degrees of freedom than the other control strategies. The slidingvelocity control strategy, due to the limitations on the expander speed, provided low flexibility and small efficiency, and resulted to be not suitable for those systems. The sliding-pressure is the simplest control strategy, however the values of efficiency and system flexibility were a function of the choice of the expander speed, and might cause a decrease of the system performance in all those case where the cycles work far from the design point.

In general, SS-OFRC allowed better performances at low HTF temperature than SS-OFC and demonstrated a wider flexibility, which makes their use really advantageous with variable heat sources: the better behavior in off-design conditions, together with the lower costs of the heat exchangers (tab. 2 and 3) and in general of the equipment [22], makes the SS-OFRC an interesting technology for low temperature WHR applications.

\section{Conclusion}

In this paper the off-design behavior of two different type of organic flash cycle architectures for WHR applications has been discussed and analyzed: the major difference between this type of architectures is the presence of a regeneration of the working fluid at the inlet of the main heat exchanger, with the liquid of the flash evaporator. I-Pentane has been selected as working fluid, due to the good efficiency provided and to the low vapor flow rate which allowed to reduce the size of both the condenser and of the expansion device. The 


\begin{tabular}{|llll|}
\hline \multicolumn{2}{l}{ Nomenclature } & \multicolumn{2}{l|}{ Subscripts } \\
$\dot{Q}$ & Thermal Power, $\mathrm{kW}$ & av & Available \\
$\dot{W}$ & Mechanical or Electrical Power, $\mathrm{kW}$ & exch & Exchanged \\
$h$ & Specific Enthalpy, kJ/kg & $N E T$ & Net \\
$\dot{m}$ & Mass flow rate, $\mathrm{kg} / \mathrm{s}$ & $i n$ & Exchanger inlet \\
$v_{g}$ & Specific volume, $\mathrm{m}^{3} / \mathrm{kg}$ & 0 & Ambient conditions \\
& & & \\
Greeks & & \\
& & & \\
$\epsilon$ & Recovery Efficiency & \\
$\eta_{c}$ & Cycle Efficiency & \\
$\eta$ & Overall Efficiency & \\
\hline
\end{tabular}

off-design evaluation of these cycles represents the basis for the analysis of the two-stage configurations which allow to achieve high efficiency. For the off-design behavior evaluation, a fixed geometry was imposed to the heat exchangers and the behavior of a rotary expander derived from a Wankel engine has been considered. Three different control strategy were analyzed: sliding-pressure, sliding-velocity and a combined strategy. The results highlighted that, whatever the control strategy adopted, SS-OFC achieved a higher efficiency than SS-OFRC at high HTF temperature, but a lower efficiency at low HTF temperature. Moreover, the operating field of SS-OFRC was larger than that of SS-OFC, due to the wider flexibility of this cycle. Among the tested control strategies the combined strategy provided the best results for both the cycles in terms of thermodynamic efficiency and flexibility, due to the larger number of control variables.

\section{References}

[1] Quoilin S, Declaye S, Legros A, Guillaume L, Lemort V. Working fluid selection and operating maps for Organic Rankine Cycle expansion machines. In: Proceedings of the international compressor and engineering conference. Purdue University; 2012.

[2] H. Zhai, Q. An, L. Shi, V. Lemort, S. Quoilin, Categorization and analysis of heat sources for organic Rankine cycle systems, Renewable And Sustainable Energy Reviews. 64 (2016) 790-805.

[3] K. Rahbar, S. Mahmoud, R. Al-Dadah, N. Moazami, S. Mirhadizadeh, Review of organic Rankine cycle for small-scale applications, Energy Conversion And Management. 134 (2017) 135-155.

[4] T. Nguyen, J. Slawnwhite, K. Boulama, Power generation from residual industrial heat, Energy Conversion And Management. 51 (2010) 2220-2229.

[5] E. Rogdakis, P. Lolos, Kalina Cycles for Power Generation, Handbook Of Clean Energy Systems. (2015) 1-25. 
[6] X. Zhang, M. He, Y. Zhang, A review of research on the Kalina cycle, Renewable And Sustainable Energy Reviews. 16 (2012) 5309-5318.

[7] P. Bombarda, C. Invernizzi, C. Pietra, Heat recovery from Diesel engines: A thermodynamic comparison between Kalina and ORC cycles, Applied Thermal Engineering. 30 (2010) 212-219.

[8] Q. Liu, A. Shen, Y. Duan, Parametric optimization and performance analyses of geothermal organic Rankine cycles using R600a/R601a mixtures as working fluids, Applied Energy. 148 (2015) 410-420.

[9] P. Mavrou, A. Papadopoulos, M. Stijepovic, P. Seferlis, P. Linke, S. Voutetakis, Novel and conventional working fluid mixtures for solar Rankine cycles: Performance assessment and multi-criteria selection, Applied Thermal Engineering. 75 (2015) 384-396.

[10] R. Shi, T. He, J. Peng, Y. Zhang, W. Zhuge, System design and control for waste heat recovery of automotive engines based on Organic Rankine Cycle, Energy. 102 (2016) 276-286.

[11] G. B. Abadi, K. C. Kim, Investigation of organic Rankine cycles with zeotropic mixtures as a working fluid: Advantages and issues, Renewable and Sustainable Energy Reviews. 73 (2017) 1000-1013.

[12] A. Schuster, S. Karellas, R. Aumann, Efficiency optimization potential in supercritical Organic Rankine Cycles, Energy. 35 (2010) 1033-1039.

[13] L. Pan, H. Wang, W. Shi, Performance analysis in near-critical conditions of organic Rankine cycle, Energy. 37 (2012) 281-286.

[14] H. Gao, C. Liu, C. He, X. Xu, S. Wu, Y. Li, Performance Analysis and Working Fluid Selection of a Supercritical Organic Rankine Cycle for Low Grade Waste Heat Recovery, Energies. 5 (2012) 3233-3247.

[15] H. Chen, D. Goswami, E. Stefanakos, A review of thermodynamic cycles and working fluids for the conversion of low-grade heat, Renewable And Sustainable Energy Reviews. 14 (2010) 3059-3067.

[16] G. Beacquin, S. Freund, Comparative performance of advanced power cycles for low-temperature heat sources, Proceedings of ECOS (2012).

[17] I. Smith, Development of the trilateral flash cycle system. part 1: fundamental considerations, Proceedings Of The Institution Of Mechanical Engineers, Part A: Journal Of Power And Energy 1990-1996 (Vols 204-210). 207 (1993) 179-194.

[18] I. Smith, R. da Silva, Development of the trilateral flash cycle system Part 2: increasing power output with working fluid mixtures, ARCHIVE: Proceedings Of The Institution Of Mechanical Engineers, Part A: Journal Of Power And Energy 1990-1996 (Vols 204-210). 208 (1994) 135-144. 
[19] T. Ho, S. Mao, R. Greif, Comparison of the Organic Flash Cycle (OFC) to other advanced vapor cycles for intermediate and high temperature waste heat reclamation and solar thermal energy, Energy. 42 (2012) 213-223.

[20] T. Ho, S. Mao, R. Greif, Increased power production through enhancements to the Organic Flash Cycle (OFC), Energy. 45 (2012) 686-695.

[21] T. Ho, Advanced Organic Vapor Cycles for Improving Thermal Conversion Efficiency in Renewable Energy Systems, Berkeley, CA, 2012.

[22] [5] A. Baccioli, M. Antonelli, U. Desideri, Technical and economic analysis of organic flash regenerative cycles (OFRCs) for low temperature waste heat recovery, Applied Energy. 199 (2017) 69-87.

[23] D. Hu, Y. Zheng, Y. Wu, S. Li, Y. Dai, Off-design performance comparison of an organic Rankine cycle under different control strategies, Applied Energy. 156 (2015) 268-279.

[24] S. Quoilin, R. Aumann, A. Grill, A. Schuster, V. Lemort, H. Spliethoff, Dynamic modeling and optimal control strategy of waste heat recovery Organic Rankine Cycles, Applied Energy. 88 (2011) 2183-2190.

[25] M. Antonelli, A. Baccioli, M. Francesconi, U. Desideri, Dynamic modelling of a low-concentration solar power plant: A control strategy to improve flexibility, Renewable Energy. 95 (2016) 574-585.

[26] B. Twomey, P. Jacobs, H. Gurgenci, Dynamic performance estimation of small-scale solar cogeneration with an organic Rankine cycle using a scroll expander, Applied Thermal Engineering. 51 (2013) 13071316.

[27] D. Wei, X. Lu, Z. Lu, J. Gu, Dynamic modeling and simulation of an Organic Rankine Cycle (ORC) system for waste heat recovery, Applied Thermal Engineering. 28 (2008) 1216-1224.

[28] J. Zhang, W. Zhang, G. Hou, F. Fang, Dynamic modeling and multivariable control of organic Rankine cycles in waste heat utilizing processes, Computers \& Mathematics With Applications. 64 (2012) 908-921.

[29] Power Plant Waste Heat Rejection Using Dry Cooling Towers, Report n EPRI CS-1324-SY, Electric Power Research Institute, February 1980.

[30] M. Antonelli, A. Baccioli, M. Francesconi, U. Desideri, L. Martorano, Operating maps of a rotary engine used as an expander for micro-generation with various working fluids, Applied Energy. 113 (2014) 742750.

[31] M. Antonelli, A. Baccioli, M. Francesconi, L. Martorano, Experimental and Numerical Analysis of the Valve Timing Effects on the Performances of a Small Volumetric Rotary Expansion Device, Energy Procedia. 45 (2014) 1077-1086. 
${ }_{459}[32]$ ASPEN HYSYS user's guide. 